\title{
Índice de fotos y pie de fotos
}

Sincretismo. Tradición, orgullo, determinación y nuevas tecnologías

Las vías. Estas vías que partieron por la mitad al territorio yaqui fueron la causa del surgimiento de Vícam Switch, el asentamiento yori en medio de tierra yoreme, llamado así porque a ese Switch (nombre genérico que los gringos daban a las estaciones por los cambios de vías) fue bautizado en honor de Pueblo Vícam, la cabecera de los Ocho Pueblos ......

Todo cabe en un carrito. Ahora no solo el tren, también una carretera de cuatro carriles cruza las comunidades yaquis. Sirve esa ruta para transportarse, para bloquearla sin es necesario y para ver cosas extravagantes... Porque todo cabe en un carrito sabiéndolo acomodar

La paz del cementerio. Con la altiva sierra del Bacatete al fondo, el descanso de los muertos parece asegurado 6

Acicale. Preparándose para la Fiesta del Cerrito (de la Santa Cruz) en Tórim. 14

Los Chivos... Pero no se confíe porque por la tarde estos congéneres de muchos maridos viqueños suelen divertirse y comer flores, si las hay

Orgullo motorizado. Haiga sido como haiga sido, pero tenemos carro

Viendo la tele. Literalmente, viendo la tele...

La bucólica estampa. Nada más bucólico y campirano que un hombre en su carreta con la sierra del Bacatete al fondo... Lo peor es que es real y convive con lo moderno, como puede verse por la cinta asfáltica bajo las patas del caballo

¡Hay Naranjas! Durante el bloqueo de la carretera internacional, los yaquis aportaron su fama y su presencia y los ricos de Obregón algunos víveres, como el diario carro de naranjas... mientras fue temporada

Brígido Jara, El Naylon. Personaje estrafalario, ícono del lugar, El Naylon fue siempre el eterno sheriff del pueblo. Los recién llegados (generalmente profesores provenientes de tierras lejanas) entraban en pánico cuando El Naylon les decía: “Hey, forastero”, al mismo tiempo que su dedo índice simulaba un cuchillo sobre el cuello

El sub-Marcos en Vícam. El Subcomandante Insurgente Marcos vino para tener el orgullo de decir que estuvo en Vícam 29

Juanón. Allí está, allí está viendo pasar el tiempo este entrañable personaje de Pótam

Conjunto rústico. Preparándose para ejecutar la música tradicional de las danzas del venado, del pascola y de los matachines (I)

\section{Savia}


La procesión del Venado. Recorrido del Venado seguido de los Pascolas. El público observa

Tradición y aprendizaje. Una tradición que los niños aprenden como jugando

Tradición e instrucción. La importancia del entrenamiento de los niños en la conservación de las tradiciones

Chapayecas en acción. En pleno Sábado de Gloria, el centro de la ceremonia es la chapayequeada (II y III)

El niño del tambor... Y el aprendizaje es su futuro .

Sumo Pascola. El fotógrafo quiso captar aquí una lejana fusión entre el pascola yaqui y el luchador de sumo japonés ...

Procesión de Chapayecas... Otros son capaces de irse a pie. No importa en que se vaya, lo que importa es llegar

El Matachín. Un retrato que capta la entrega, la ceremonia y la pasión con que se llevan a cabo las tradiciones

El viejito del tambor. La experiencia es la base de la conservación de las tradiciones...

La oradora. Campeona de oratoria por el privilegio de ser bilingüe (español-lengua yaqui)

El Siux. Vino al encuentro continental de los pueblos indígenas y capturó las miradas de los ojos femeninos que habían visto hasta entonces solo ejemplares locales.

El Niño de Pótam. Infancia y pobreza: la desgarradora realidad en las comunidades yaquis ......

El niño cuentista. Este niño yaqui de las Guasimitas (un pequeño rancho entre Vícam y Pótam, yendo por el campo) escribe cuentos. Ya ganó un premio y el gobierno federal, generoso que es, le dio una laptop

Tutuli la Chavela. Fue al Cerro Metetoma nomás para atestiguar el regreso de los guerreros yaquis (desde el museo metropolitano de Nueva York) a su territorio

Mujer sentada en piedra. Tomándose un descanso antes de empezar la procesión de la Fiesta del Cerrito en Tórim

Testigo presencial. Como si reflexionara sobre el pasado, esta viejita llegó temprano para ver el desfile de Independencia

María Matuz. Se puede decir que ella, como curandera, era la última frontera de la esperanza 40

La del reboso blanco. Para el tiempo de calor, el blanco es el indicado 41

Caminando bajo la lluvia. Protegiendo los zapatos del lodazal

Vía libre. Es tal el desastre ferroviario nacional que se puede caminar sobre las vías sin el peligro de que venga el tren

La carga del mandado. Mujer yaqui cargando el mandado rumbo a su casa

Rosario por los guerreros. Ceremonia en honor del regreso de los restos de los guerreros yaquis masacrados por el ejército en 1902 en la sierra de Mazatán. Los 107 cuerpos fueron llevados a los Estados Unidos y allá permanecieron, en el Museo de Historia Natural de Nueva York, hasta el 2007.

Fiesta de San Juan en Pueblo Vícam V. Los habilidosos jinetes se arriesgan para ganar el premio por sacar el gallo enterrado a pleno galope en la Fiesta de San Juan en Pueblo Vícam

Reverencia por los guerreros. Profundo respeto por los restos de los guerreros yaquis

12 que no están

Jamu yuuma (El poder de las mujeres). El poder de las mujeres es tan grade entre los yaquis que su influencia en cualquier ceremonia es imprescindible. Aquí, en el entierro en el cerro Metetoma de los guerreros yaquis

Vestimenta típica de mujeres yaquis. Un grupo de mujeres yaquis posa para la cámara del Vícam Switch para mostrar con ello el orgullo por sus tradiciones... aunque las prendas modernas busquen ocupar un lugar

Velorio de la María Matuz. Un tapesti de carrizo y la iglesia como velatorio es la forma en que se llevan a cabo los funerales de los grandes 